\title{
INFLUÊNCIA DO LAZER SOBRE PESSOAS DA TERCEIRA IDADE
}

\author{
* Joviana Borges de QUEIROZ \\ * Sonia de Fátima TRINCA
}

$\operatorname{ReBEn} / 09$

QUEIROZ, J. B. e Colaboradora - Influência do Lazer Sobre Pessoas da Terceira Idade. Rev. Bras. Enf: RS, 36: $\quad 95-106,1983$.

\section{R E S U M O}

Com esta pesquisa procurou-se descobrir até que ponto o lazer pode ser importante na sociabilização da pessoa da terceira idade.

As hipóteses de que o lazer é procurado como fuga à solidão e como um passatempo sem finalidade nortearam todo procedimento da pesquisa.

A pesquisa foi realizada em duas Instituições em Bauru - SP, que se dedicam de uma forma ou de outra à assistência do idoso; ambas apresentam características administrativas e assistenciais diversas.

Os dados necessários foram levantados com o uso de questionário aplicado com 40 (quarenta) pessoas idosas.

Os resusltados foram apresentados em percentual e dispostos em tabelas.

Discutidos e analisados os resultados obtidos foi possível demonstrar a veracidade de que o lazer é procurado como fuga à solidão e como um passatempo sem finalidade.

Com base nos resultados, foi sugerida também uma programação de lazer para as instituições.

\section{0 - INTRODUÇÃO}

Pretendeu-se, com esta pesquisa de campo, avaliar até que ponto o lazer pode influenciar na sociabilização do idoso.

Os autores consultados relatam que o lazer é necessário em qualquer época da vida. Deve ele fazer parte do tempo a ser utilizado pelas pessoas, assim como o é também o do trabalho.

O lazer é imprescindível à manutenção da saúde e mesmo à auto-valorização na fase mais adiantada da vida, ou seja, na terceira idade.

Há pessoas que poderiam sentir-se ainda úteis de uma forma ou de outra, nesta ou naquela atividade; entretanto, o desuso de diferentes segmentos corporais, afastam-nos, até mesmo de um convívio social sadio. Acham-se incapazes e desvalorizados. Esse sentimento de marginalização é prejudicial à vida do corpo e do espírito. Pode-se aplicar aqui o que os antigos filósofos diziam: "corpo são, mente sa्a."

* Alunas do Curso de Graduação em Enfermagem

$$
\text { Bauru - } 1982
$$


QUEIROZ, J. B. e Colaboradora - Influência do Lazer Sobre Pessoas da Terceira Idade. Rev. Bras. Enf: RS, 36: $95-106,1983$.

É necessário que o homem se convença que não é só o trabalho que dá sentido à vida. As energias renovadas pelo lazer, poderão trazer-the incentivo, otimismo e sempre mais esperanças.

O progresso tecnológico trouxe maior dilatação do tempo livre e a correspondente contração do tempo de trabalho. Esta situação faz com que a sociedade mude e supere preconceitos. Conseqüentemente o lazer deixa de ser privilégio de classe e passa ter dimensão social. O homem, participando de atividades de lazer, poderá estabelecer relações com o meio e com o mundo; esta condição favorece o inter-relacionamento das pessoas, contribuindo para viver melhor.

Se o homem não souber aproveitar devidamente o tempo disponível, poderá sentir-se insatisf eito, inseguro e irrealizado. Aos poucos poderá sentir-se angustiado e isolado.

Atualmente a pessoa da terceira idade é relegada a segundo plano pela sociedade que utiliza-se apenas de jovens exigindo a sua plena participação nas atividades da sociedade; esquece que também o idoso necessita do convívio social e poderá até contribuir para o seu desenvolvimento, bastando propiciar-lhe ambiente apropriado. Poderá também ocorrer que o idoso procure o lazer como uma fuga de sua solidão por sentir-se angustiado e desvalorizado; outras vezes prefere viver em constante isolamento social prejudicando consideravelmente a sua sensibilidade.

Todo idoso deve sentir-se incentivado a participar de atividades de lazer e executar tarefas que antes eram importantes para ele. $O$ lazer poderá então ser um veículo de educação.

O lazer procurado como fuga à solidão e como um passatempo sem finalidade, são as hipóteses levantadas.

\section{0 - DEFINIÇĀO DE TERMOS}

"Lazer significa, um conjunto de ocupações às quais o indivíduo pode entregar-se de livre vontade, seja para repousar, seja para divertir-se, recrear-se e entreter-se ou, ainda, para desenvolver sua informação ou formação desinteressada, sua participação social voluntária ou sua livre capacidade criadora após livrar-se ou desembaraçar-se das obrigações profissionais, familiares e sociais" (DONFUT, Claudine Attias).

"Velhice é entendida como uma etapa da vida na qual, em decorrência da alta idade cronológica, ocorrem modificações de ordem biopsicossocial que afetam a relação dos indivíduo com o meio".

Socialização ou Sociabilização como apareceu antes:

"Processo pelo qual o individuo, no sentido bilógico, é integrado numa sociedade. Pela socialização o indivíduo se torna pessoa humana, adquirindo os hábitos que o capacitam para viver numa sociedade. Socialização significa aprendizagem ou educafão, no sentido mais lato da palavra, aprendizagem essa que começa na primeira infância e termina com a morte da pessoa. A medida que a socialização implica a dominação de certos impulsos indesejáveis, ela pode ser definida, também, como série de ajustamentos a determinados padröes cultuSociabilidade : rais" (1).

"Em sentido corrente, é a qualidade de quem é sociável, ou seja, de quem tem o dom do relacionamento fácil e cordial com todos. E uma qualidade que pode e deve ser adquirida, porque é indispensável para um convivio social harmonioso e feliz. Ela se adquire pelo controle permanente do nosso egoísmo e pelo exercicio daquelas virtudes que esperamos encontrar nos outros, especialmente a discrição, a lealdade e a dedicação" (2).

\section{0 - REVISĀO DA LITERATURA}

Em sua obra, DONFUT (1980), menciona que o lazer na terceira idade decorre do considerável aumento de tempo livre que a pessoa adquire devido ao fato de parar de trabalhar. $\mathrm{O}$ lazer, evidentemente, não é mais formulado da mesma maneira nessa faixa etária como era para as outras.

(1) Dicionário de Sociologia, Porto Alegre, Globo, 1970, p. 312.

(2) Pequena Enciclopédia de Moral e Civismo, FENAME, 1972, p. 617. 
QUEIROZ, J. B. e Colaboradora - Influência do Lazer Sobre Pessoas da Terceira Idade. Rev. Bras. Enf: RS, 36: 95-106, 1983.

Entre os aspectos de lazer ligados às pessoas idosas, relata também a manifestação visível da capacidade dos idosos criarem o tédio, o vazio, ou, ainda, outras formas de patologias sociais, processo do qual entram outros elementos além do lazer, como o isolamento social, onde desempenha um papel negativo.

DONFUT (1979), fez, também, referência sobre os conflitos gerados em torno do lazer relacionados com as diferenças existentes entre as classes sociais e as diferentes faixas etárias. O lazer dever ter início na infância persistitndo sempre da melhor maneira possível, até à velhice. Quando as pessoas vão alcançando determinada idade vão cessando de trabalhar e, por si mesmas, procuram coisas para fazer. Donfut conclui que o lazer á apenas aquilo que é dedicado para o desenvolvimento de sua própria personalidade.

DUMAZEDIER (1980), relata que o lazer é uma atividade mista onde misturam-se obrigação institucional, tendo características que preenchem as necessidades humanas como o descanso, divertimento e o desenvolvimento permitindo ao homem uma participação social maior e livre.

É necessário, portanto, dentro do desenvolvimento do lazer, distinguir as atividades, gêneros de conhecimento e níveis culturais para que tenha um controle desse lazer, possibilitando um maior conhecimento para que sejam atingidos todos os objetivos a que se propõe, sejam eles culturais ou sociais.

FARIA (1977), refere que é muito importante que o lazer faça parte da nossa vida, sendo um dos meios mais eficazes para se relaxar de todas as tensões, Não se deve ficar sujeito somente a trabalhos e preocupações, sem deixar alguns momentos para a recreação.

Os velhos, preocupados por não poderem contribuir mais com u m trabalho útil à sociedade, vão se definhando em sua tristeza até a morte chegar. Por isso, deve-se incentivar a terapia ocupacional, a ginástica, o artezanato, bem como atividades recreativas que trazem conforto e uma vida espiritual tranqüila aos velhos.

PARENTE FILHO (1978), fala que o lazer não é descanso do trabalho, ele só existe como algo além do trabalho e além do descanso.

E muito importante que o homem tenha um lazer criativo, na tentativa de amenizar a vida e torná-la mais alegre, do que ter um lazer passivo, sem algum benefício para o desenvolvimento.

Devemos lembrar que o lazer não é um passatempo qualquer, mas é a recuperação do primitivo dentro da gente.

REQUIXA (1976), cita que as atividades de lazer são importantes tendo como função a atenuação ou mesmo superação de problemas que influenciam, de forma direta e individual, o homem.

Funciona como repouso, prevenção e recuperação psicossomática entre as pessoas de todas as idades sendo necessário o contato social, principalmente entre os idosos, para que descubram suas próprias possibilidades e passem a agir e a pensar menos condicionalmente. Espera-se que o lazer possa provocar, em seus participantes. interesses voltados para objetivos sociais.

REQUIXA (1980), refere-se à necessidade de implantação de política nacional do lazer que visa a necessidade de criar espaços destinados à prática do lazer favorecendo melhorés condições sócioculturais para que sejam desenvolvidas atividades lúdicas pelo aperfeiçoamento de instrumentos e de recursos humanos apropriados.

O homem precisa ser educado para o lazer; assim poderá aproveitar todo o tempo disponível e sentir plena satisfação de viver e não tédio, de pressão e solidão.

SALGADO (1980), diz que a velhice é uma etapa da vida humana. Conseqüentemente, com aumento da idade cronológica, ocorrem modificações, de ordem biopsicossocial que afetam a relação do indivíduo com o meio ambiente. Em decorrência dessa situação são necessários estímulos bem maiores para que os idosos entrem em atividade novamente.

Os idosos devem ser preparados para a aposentadoria, orientados para a prática do lazer. Isto evita-se que fiquem isolados, o que poderia levá-los à solidão. Através do lazer deve ser estimulada a atividade cultural, intelectual, física, manual e artística, levando ao combate do isolamento social.

TEIXEIRA (1977), fala que a escolha do lazer, deve ser em nível individual ou nível nacional, de acordo com três tipos de recursos: tempo, espaço e dinheiro.

Com o desenvolvimento econômico e o progresso tecnológico, as pessoas estão tendo um tempo mais disponível para o lazer, tanto para os que são realizados nas residências próprias como para os que exigem instalações especiais. Portanto, o tipo de lazer a escolher dependerá muito da distribuição de renda e dos padrões sócio-culturais. 
QUEIROZ, J. B. e Colaboradora - Influência do Lazer Sobre Pessoas da Terceira Idade. Rev. Bras. Enf: RS, 36: 95-106, 1983.

\section{0 - METODOLOGIA}

Paulo.

A pesquisa foi realizada em dois locais distintos, em uma das cidades do interior de São

Para fins operacionais, os locais foram identificados com as letras A e B, e o total de pessoas idosas assistidas nesses locais está discriminado no quadro que segue:

QUADRO 1 - Total de Pessoas Idosas dos Locais A e B:

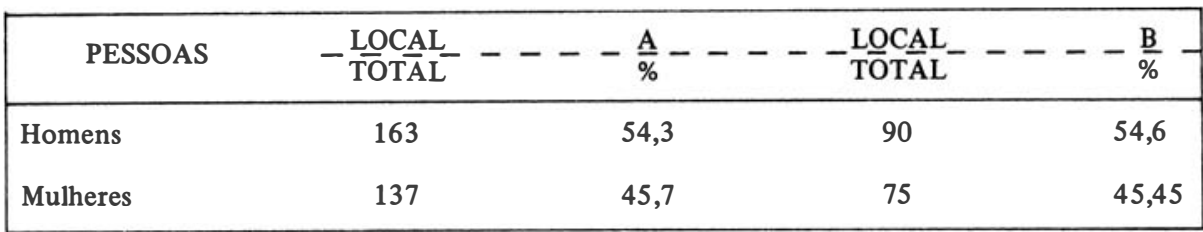

Fonte: Fichário das Instituições

Nota: 40 leitos são destinados aos doentes.

O local A caracteriza-se por uma escola aberta para os idosos, com o objetivo de integrá-los na sociedade. Existe também programação especial denominada de Centro de Convivência da Terceira Idade. $\mathrm{O}$ propósito é de conduzir o idoso ao lazer, à cultura, à sociabilização e às atividades físicas. Consta no fichário, um total aproximado de 300 (trezentas) pessoas. Dessas, 80 (oitenta) participam de ginástica de conservação nas terças feiras, no período vespertino; os demais, participam de atividades lúcidas como: bocha, malha, biodança, coral, buraco, snooker, dominó, truco, ping-pong e dama. A idade média das pessoas que freqüentam o local A é de 52 anos. Estas pessoas residem no lar, ou com os filhos ou apenas o casal.

O local B, caracteriza-se pelo fato de of erecer hospedagem, tipo internato, para idosos acima de 50 anos. Atualmente residem 165 (cento e sessenta e cinco) idosos, sendo 75 (setenta e cinco), $(45,45 \%)$ são mulheres e 90 (noventa), $(54,6 \%)$ homens. A média é de 69 (sessenta e nove) anos. O local B dispõe de 40 (quarenta) leitos para os doentes; no momento, os 40 (quarenta) leitos estão ocupados.

Não há programação regular de lazer para as pessoas; os homens ficam livres para realizar o que desejarem, como trabalhos gerais e jogos. As mulheres utilizam o tempo para artesanatos. Aos domingos, no período vespertino, há brincadeiras dançantes. Recebem visitas às quintas-feiras e aos domingos, a partir das $14: 00$ horas.

Financeiramente a entidade recebe a juda governamental; além disso, há anualmente festa beneficiente e outras atividades desse gênero. Poucas pessoas que lá residem, recebem ajuda financeira da família.

\section{1 - Universo e Amostra}

Determinou-se que constariam da amostra um total de 20 (vinte) pessoas de cada instituição. O percentual da Instituição A é representada por $25,0 \%$ de pessoas e do B por $12,1 \%$ de pessoas. Critérios para a determinação da amostra: Os idosos inclu ídos na amostra deveriam:

1. ter idade de 50 a 60 anos, não considerando o sexo;

2. ser capazes de responder o questionário sozinhos ou ajudados pelos pesquisadores.

\section{2 - Instrumento}

A coleta de dados foi realizada através de um questionário elaborado com quinze perguntas, sendo todas fechadas. Pretendeu-se com isto avaliar a influência que o idoso recebe nos locais onde são of erecidas condições para o lazer. Explora recursos que poderiam ajudar as pessoas idosas a sentirem-se mais valorizadas, onde as condições são mais precárias. 
QUEIROZ, J. B. e Colaboradora - Influência do Lazer Sobre Pessoas da Terceira Idade. Rev. Bras. Enf: RS, 36: 95-106, 1983.

\section{3 - Procedimento de Coleta de Dados}

O questionário foi aplicado no local $\mathrm{A}$ nas terças e quintas feiras da 14:00 horas às 16:00 horas. Isto porque, nestes dias, o grupo que freqüenta o local A é quantitativamente maior em relação aos outros dias. As atividades de terça-feira são ginástica de conservação e reuniões de grupo. As atividades de quinta-feira são ginástica de grupo e coral.

No local B foi aplicado, nas quintas-feiras e domingos, a partir das 14:00 horas. Isto porque houve necessidade de uma acompanhante da instituição que acompanha os pesquisadores. Esta situação formou-se porque os idosos do local B sentem-se constrangidos e sobretudo temerosos quando respondem algo para pessoas estranhas. Em companhia de pessoas conhecidas ficou mais fácil a comu.nicação e a obtenção das informações necessárias.

\section{0 - RESULTADOS OBTIDOS}

belas que seguem:

TABELA 1 - Importância do lazer apreciado pelos respondentes do Grupo A - Maio de 1982.

\begin{tabular}{lcccccc}
\hline \multicolumn{1}{c}{ VARIĀVEIS } & SIM & $\%$ & NĀO & $\%$ & TOTAL & $\%$ \\
\hline $\begin{array}{l}\text { Procura atividades de lazer, porque } \\
\text { sentia-se sozinho. }\end{array}$ & 12 & 60,0 & 08 & 40,0 & 20 & 100 \\
$\begin{array}{l}\text { Sempre que tem um tempo livre costu- } \\
\text { ma fazer alguma coisa. }\end{array}$ & 19 & 95,0 & 01 & 5,0 & 20 & 100 \\
$\begin{array}{l}\text { Sente-se incentivado para procurar o la- } \\
\text { zer. }\end{array}$ & 14 & 70,0 & 06 & 30,0 & 20 & 100 \\
$\begin{array}{l}\text { Atividade de lazer que escolhe é rear- } \\
\text { mente do seu agrado. }\end{array}$ & 20 & 100,0 & -- & -- & 20 & 100 \\
$\begin{array}{c}\text { Através das atividades de lazer desco- } \\
\text { briu alguma que the dá maior prazer. }\end{array}$ & 17 & 85,0 & 03 & 15,0 & 20 & 100 \\
$\begin{array}{l}\text { Sente-se feliz desempenhando atividade } \\
\text { de lazer. }\end{array}$ & 20 & 100,0 & -- & -- & 20 & 100 \\
$\begin{array}{c}\text { A partir do momento que começou a } \\
\text { participar de alguma atividade de la- } \\
\text { zer, sentiu alguma influência impor- } \\
\text { tante onde vive. }\end{array}$ & 18 & 90,0 & 02 & 10,0 & 20 & 100 \\
$\begin{array}{c}\text { Acha importante estas atividades re- } \\
\text { creativas, junto com as pessoas de } \\
\text { mesma idade. }\end{array}$ & 20 & 100,00 & -- & -- & 20 & 100 \\
\hline
\end{tabular}

FONTE: Questionário Aplicado.

A Tabela 1 mostra que $100 \%$ das atividades realizadas foram do agrado de todos, assim como o estilo de atividades realizadas e a satisfação de passar esses momentos com outras pessoas da mesma idade.

Observa-se que $60,0 \%$ dos respondentes participam de atividades de lazer porque se sentem sozinhos. Entretanto, 70,0\% sentem-se incentivados e fazem alguma atividades de lazer.

Os idosos representados em $90,0 \%$ consideram que em atividades de lazer, há possibilidade de dialogar com outras pessoas, recebendo, assim influências do meio social onde vivem. 
QUEIROZ, J. B. e Colaboradora - Influência do Lazer Sobre Pessoas da Terceira Idade. Rev. Bras. Enf: RS, 36: 95-106, 1983.

TABELA 2 - Como os Idosos do Grupo A consideram os jovens.

\begin{tabular}{ccccccc}
\hline VARIÃVEIS & SIM & $\%$ & NÃO & $\%$ & TOTAL & $\%$ \\
\hline Os jovens aceitam a pessoa idosa. & 04 & 20,0 & 16 & 80,0 & 20 & 100 \\
Os jovens rejeitam a pessoa idosa. & 14 & 70,0 & 06 & 30,0 & 20 & 100 \\
\hline
\end{tabular}

FONTE: Questionário Aplicado.

Os idosos acham que $80,0 \%$ dos jovens não aceitam o idoso, enquanto que $20,0 \%$ dizem que sim. Sendo que $70,0 \%$ concordam que o jovem rejeita o idoso e $30,0 \%$ não.

TABELA 3 - Finalidade pela qual os idosos do grupo A procuram o lazer.

\begin{tabular}{ccccccc}
\hline VARIÁVEIS & SIM & $\%$ & NÃO & $\%$ & TOTAL & $\%$ \\
\hline $\begin{array}{l}\text { Procura o lazer como um passatempo } \\
\text { sem finalidade. }\end{array}$ & 09 & 45,0 & 11 & 55,0 & 20 & 100 \\
Procura o lazer como fuga da solidão. & 11 & 55,0 & 09 & 45,0 & 20 & 100 \\
\hline
\end{tabular}

FONTE: Questionário Aplicado.

O lazer é procurado como um passatempo sem finalidade, por $45,0 \%$, enquanto que $55,0 \%$ responderam não. O lazer é procurado como uma fuga da solidão por $55,0 \%$ e $45,0 \%$ acha que não é por fuga da solidão.

TABELA 4 - Quando jovens, como os idosos do Grupo A sentiam-se em relação ao trabalho e ao lazer

\begin{tabular}{lcccccc}
\hline VARIÁVEIS & SIM & $\%$ & NÃO & $\%$ & TOTAL & $\%$ \\
\hline $\begin{array}{l}\text { Foi uma pessoa que sentiu-se realizada } \\
\text { no trabalho que fazia. }\end{array}$ & 16 & 80,0 & 04 & 20,0 & 20 & 100 \\
$\begin{array}{l}\text { Preocupou-se com o lazer também } \\
\text { quando era mais novo. }\end{array}$ & 07 & 35,0 & 13 & 65,0 & 20 & 100 \\
$\begin{array}{l}\text { Incentivou os companheiros para ativi- } \\
\text { dades de lazer também quando era } \\
\text { mais novo. }\end{array}$ & 06 & 30,0 & 14 & 17,0 & 20 & 100 \\
\hline
\end{tabular}

FONTE: Questionário Aplicado.

Dos idosos, $80,0 \%$ sentem-se realizados na sua vida enquanto exerciam o seu trabalho e $20,0 \%$ não. Somente $35,0 \%$ preocupou-se com o lazer quando mais novo, enquanto $65,0 \%$ não se preocupou.

Encontramos uma porcentagem de apenas $30,0 \%$ dos idosos que incentivaram os companheiros ao lazer quando mais novos, e $70,0 \%$ responderam em negação. 
QUEIROZ, J. B. e Colaboradora - Influência do Lazer Sobre Pessoas da Terceira Idade. Rev. Bras. Enf: RS, 36: 95-106, 1983.

TABELA 5 - Importância do lazer apreciados pelos respondentes do Grupo B - Maio de 1982.

\begin{tabular}{lcccccc}
\hline VARIÁVEIS & SIM & $\%$ & NÃO & $\%$ & TOTAL & $\%$ \\
\hline $\begin{array}{c}\text { Participa de atividades de lazer, por- } \\
\text { que sentia-se sozinho. }\end{array}$ & 11 & 55,0 & 09 & 45,0 & 20 & 100 \\
$\begin{array}{c}\text { Sempre que tem um tempo livre costu- } \\
\text { ma fazer alguma coisa. }\end{array}$ & 15 & 75,0 & 05 & 25,0 & 20 & 100 \\
$\begin{array}{c}\text { Sente-se incentivado para procurar o la- } \\
\text { zer. }\end{array}$ & 08 & 40,0 & 12 & 60,0 & 20 & 100 \\
$\begin{array}{c}\text { A atividade de lazer que escolhe é real- } \\
\text { mente do seu agrado. }\end{array}$ & 16 & 80,0 & 04 & 20,0 & 20 & 100 \\
$\begin{array}{c}\text { Através das atividades de lazer desco- } \\
\text { briu alguma que lhe dá maior prazer. }\end{array}$ & 10 & 50,0 & 10 & 50,0 & 20 & 100 \\
$\begin{array}{c}\text { Sente-se feliz desempenhando atividade } \\
\text { de lazer. }\end{array}$ & 17 & 85,0 & 03 & 15,0 & 20 & 100 \\
$\begin{array}{c}\text { A partir do momento que começou a } \\
\text { participar de alguma atividade de } \\
\text { lazer, sentiu alguma influência onde } \\
\text { vive. }\end{array}$ & 12 & 60,0 & 08 & 40,0 & 20 & 100 \\
$\begin{array}{c}\text { Acha importante estas atividades de la- } \\
\quad \text { zer, serem realizadas junto com as } \\
\text { pessoas da mesma idade. }\end{array}$ & 19 & 95,0 & 01 & 5,0 & 20 & 100 \\
\hline
\end{tabular}

FONTE: Questionário Aplicado.

Pelo questionário aplicado aos idosos, observa-se que $55,0 \%$ procuram o lazer por sentirem-se sozinhos e somente $40,0 \%$ são incentivados a participar de atividades de lazer. Sempre que têm um tempo livre, $75,0 \%$ dos idosos procuram fazer alguma coisa.

Entretanto, $80,0 \%$ dos idosos escolhem atividades de lazer do seu agrado, assim, 50,0\% participam das atividades que thes dão prazer, levando a $85,0 \%$ dos idosos a sentirem-se felizes.

Entre us respondentes, $60,0 \%$ observou mudança na sua vida, e $95,0 \%$ acha importante as atividades de lazer realizadas com pessoas de mesma idade.

TABELA 6 - Como os idosos do Grupo B consideram os jovens.

\begin{tabular}{ccccccc}
\hline VARIÁVEIS & SIM & $\%$ & NÃO & $\%$ & TOTAL & $\%$ \\
\hline Os jovens aceitam os idosos. & 15 & 75,0 & 05 & 25,0 & 20 & 100 \\
Os jovens rejeitam os idosos. & 07 & 35,0 & 13 & 65,0 & 20 & 100 \\
\hline
\end{tabular}

FONTE: Questionário Aplicado.

Dos 20 (vinte) respondentes, $75,0 \%$ acham que os jovens aceitam os idosos, enquanto que $25,0 \%$ sentem-se rejeitados pelos jovens. 
QUEIROZ, J. B. e Colaboradora - Influência do Lazer Sobre Pessoas da Terceira Idade. Rev. Bras. Enf: RS, 36: 95-106 , 1983.

TABELA 7 - Finalidade pelo qual os idosos do Grupo B procuram o lazer.

\begin{tabular}{ccccccc}
\hline VARIÅVEIS & SIM & $\%$ & NÃO & $\%$ & TOTAL & $\%$ \\
\hline $\begin{array}{l}\text { Procura o lazer como um passatempo } \\
\text { sem finalidade. }\end{array}$ & 13 & 65,0 & 07 & 35,0 & 20 & 100 \\
Procura o lazer como fuga da solidão. & 14 & 70,0 & 06 & 30,0 & 20 & 100 \\
\hline
\end{tabular}

FONTE: Questionário Aplicado.

Pelos resultados obtidos, observa-se que $65,0 \%$ dos idosos procuram o lazer como um passatempo sem finalidade, enquanto que $70,0 \%$ procuram o lazer como fuga da solidão. Mais de $50,0 \%$ deles, não têm objetivo específico ao procurar o lazer.

TABELA 8 - Quando jovens, como os idosos do Grupo B sentiam-se em relação ao trabalho e ao lazer.

\begin{tabular}{ccccccc}
\hline VARIĀVEIS & SIM & $\%$ & NĀO & $\%$ & TOTAL & $\%$ \\
\hline $\begin{array}{c}\text { Foiuma pessoa que se sentiu realizada } \\
\text { no trabalho que fazia quando jovem. }\end{array}$ & 16 & 80,0 & 04 & 20,0 & 20 & 100 \\
$\begin{array}{c}\text { Preocupou-se com o lazer também } \\
\text { quando era mais novo. }\end{array}$ & 14 & 70,0 & 06 & 30,0 & 20 & 100 \\
$\begin{array}{c}\text { Incentivou os companheiros para ativi- } \\
\text { dades de lazer quando era mais novo. }\end{array}$ & 09 & 45,0 & 11 & 55,0 & 20 & 100 \\
\hline
\end{tabular}

FONTE: Questionário Aplicado.

A grande maioria dos idosos, $80,0 \%$, sentem-se realizados com o trabalho que faziam quando jovem e $20,0 \%$ não. Ainda quando mais novos, muitos deles, $70,0 \%$, preocupavam-se com o lazer e apenas $30,0 \%$ responderam negativamente. Somente $45,0 \%$ incentivaram amigos para participar de atividades de lazer e 55,0\% não.

\section{0 - ANÅLISE E DISCUSSĀO DOS DADOS}

Dos idosos do grupo A, $100 \%$ consideram que a atividade de lazer causa-lhes prazer, destacando a importância da oportunidade de dialogar com pessoas da mesma faixa etária. Os do grupo B, confrontados com os do Grupo A, não tiveram a mesma apreciação; $80,0 \%$, dos idosos consideram que a atividade de lazer é de seu agrado; porém $95,0 \%$ também consideram muito importante realizar atividades desse gênero com pessoas da mesma idade.

Nos dois grupos, observa-se que mais de $50,0 \%$ dos respondentes, participam de atividades de lazer, porque se sentem sozinhos; esta situação mostra que há falta de programas sociais na família e, provavelmente, nos encontros com grupos sociais. TEIXEIRA diz que o tipo de lazer a escolher tanto nas residências como fora dela, depende das condições financeiras e dos padrões sócio-culturais de cada um.

Embora os idosos do Grupo A participam de atividades de lazer, especialmente programados por entidades que se dedicam à assistência do idoso, $60,0 \%$ procurou u suf ruir desse recurso, porque sentia-se só e não como uma necessidade. Observou-se, porém que nos dois grupos, os idosos procuram fazer alguma coisa: no grupo "A" $5,0 \%$ não se interessavam a fazer algo e no grupo "B" $25,0 \%$.

As Tabelas 2 e 6 mostram que a aceitação do idoso pelo jovem é muito maior, $75,0 \%$ nos pertencentes do grupo " $B$ " mais do que os do grupo " $A$ ", onde $80,0 \%$ dos jovens não aceitam o idoso. Como se explica essa rejeição dos jovens aos idosos? São as facilidades que a família of erece aos jovens 
QUEIROZ, J. B. e Colaboradora - Influência do Lazer Sobre Pessoas da Terceira Idade. Rev. Bras. Enf: RS, 36: 95-106, 1983.

em ternnos de conforto ou de outros recursos? O que leva à aceitação dos idosos do grupo "B"? São as condições mais difíceis da vida? ou a pouca sorte de recursos? A experiência do trabalho transmitida pelos idosos aos jovens? ou a aceitação é sentida mais positivamente porque pessoas jovens visitando esses idosos, empregavam tempo para conversar com eles e ouvi-los? Esta possibilidade poderá ser aceita porque os pesquisadores tiveram a oportunidade de observar situações semelhantes à referida.

A rejeição dos jovens pelos idosos do grupo "A", pode também ser confirmada pelas experiências por eles sentidas. Trata-se de "insultos" a eles dirigidos quando estão em atividades fora do lar. São todas hipóteses levantadas, que of erecem possibilidades para outras investigações.

Em relação à finalidade da procura do lazer pelos idosos dos grupos A e B, observa-se que $55,0 \%$ do primeiro grupo procurava o lazer como fuga da solidão e com $70,0 \%$ do segundo grupo ocorre essa mesma finalidade. Esses dados vêm confirmar a primeira variável das tabelas no 1 e no 5 , que se referem que os idosos procuravam o lazer porque se sentiam sozinhos. E de se notar também que os idosos do grupo B, num percentual de $65,0 \%$ tinham o lazer apenas como um passatempo sem finalidade. PARENTE FILHO, lembra que o lazer não é um passatempo qualquer, por isso é importante despertar no homem o interesse pelo lazer.

As tabelas n? 4 e no 8 demonstram como os idosos sentiam-se em relação ao trabalho e ao lazer. E curioso perceber a igualdade de sentimento, manifestado por eles; $80,0 \%$ sentiu-se realizado no trabalho que realizava.

Considerando a preocupação do lazer quando jovens, os idosos do grupo "B" mostraram maior interesse do que os do grupo " $A$ ", enquanto que no grupo " $B$ " 70,0\% e no grupo " $A$ " $35,0 \%$ de preocupação. Nota-se também que, apesar de haver maior interesse pelo lazer com os idosos do grupo B, apenas $45,0 \%$ incentivaram companheiros a esse tipo de atividade; os do grupo "A", 30,0\% tiveram esse tipo de incentivo. Essas informações coincidem com os dados anteriores referidos. Os idosos do grupo " $A$ ", hoje participando de atividades de lazer têm oportunidades de incentivar mais idosos para juntarem-se a eles.

\section{0 - CONCLUSĀO}

Com esta pesquisa pôde-se constatar como o lazer é importante na vida da pessoa idosa. $\mathrm{O}$ idoso percebe as coisas de maneira diferente, dando sentido às que se propõe a fazer.

As hipóteses do lazer como fuga da solidão e como passatempo sem finalidade foram comprovadas. Das pessoas do grupo A, 60,0\% procuram o lazer não como algo que está naturalmente integrado à própria vida.

Deve-se ressaltar também que $90,0 \%$ das pessoas idosas consideram importante o convívio com pessoas da mesma faixa etária porque facilita o desempenho nas atividades de lazer.

Percebe-se ainda que nos idosos do grupo B, a maioria interessava-se pelo lazer quando jovens e inventivavam outras pessoas. No grupo A, porém tal incentivo é maior agora. Os idosos sentem a necessidade de participar de atividade de lazer porque sentem-se sozinhos. Com isto têm a oportunidade de se deslocar de suas residências e se divertirem em locais apropriados como o local A. Eles não são obrigados a participarem de atividades que não gostam, mas apenas daquelas que sentem vontade esquecendo um pouco de sua solidão. Já no grupo B, eles não tem oportunidade de desempenharem atividades que gostam e sim apenas as existentes na entidade, sendo poucas as opções.

\section{0 - SUGESTĀO}

Em se tratando do valor educativo que o lazer proporciona e os benefícios de âmbito físico, espiritual e social, sugere-se que se realize organização de atividades desse gênero em abrigos de velhos, principalmente. Poderão ter a oportunidade de freqüentar regularmente essas atividades e amenizar, em parte, as limitações físicas, próprias desse período da vida.

Como o lazer tem implicações sociais e está na dependência de padrões culturais e de condições sócio-econômicas, sugere-se também a organização de um centro de lazer em lugares determinados da comunidade onde o acesso aos interessados fosse facilitado. Poderia ser um centro de experiência que poderia fazer parte da formação do estudante de enfermagem.

Os benefícios proporcionados às pessoas idosas, seriam a recompensa a seus organizadores. 
QUEIROZ, J. B. e Colaboradora - Influência do Lazer Sobre Pessoas da Terceira Idade. Rev. Bras. Enf: RS, 36: $95-106,1983$.

\section{SUMMARY}

In this research we have tried to find out the important of leisure in the process of soiavilization of persons in the third age.

The hypothesis are that leisure is looked for as a means of escaping solitude, as a hobby without aims. These facts lead the proceduces in the research.

The research was accomplished in two. Institutions in Bauru, São Paulo, which deal with the assistence of old persons; both presenting different administrative and assistencial characteristics.

The necessary data were achieved using a set of questions answered by forty old persons.

The results were presented in percentages and desposed in tables.

After discussing and analiging the results it was possible to demonstrate that leisure is indeed a means of escaping solitude and as a passtime without specific purposes.

Based on the results, a program of leisure was suggested to both Institutions.

\section{REFERENCIAS BIBLIOGRÅFICAS}

01. DONFUT, Claudine Attias. Seminário de Estudos Sobre a Terceira Idade. Cadernos da Terceira Idade, São Paulo, SESC, fev./1979.

$02 . \quad$.Cadernos da Terceira Idade, n? 5, São Paulo, CETI, 1980, p. 7 - 10.

03. DUMAZEDIER, Jof re. A Teoria Sociológica da Decisão. Série Lazer no 1, São Paulo, SESC, 1980 , p. 1 - 36.

04. FARIA, Carlos Coelho. Velhice é Preconceito. São Paulo, BISORDI, 1977, p. 45 - 48.

05. PARENTE FILHO, José Inácio de Sá. Lazer e Psicologia Preventiva. Cadernos de Lazer n 9 3. São Paulo, Brasiliense, 1978. p. 51-60.

06. REQUIXA, Renato. Cadernos de Lazer, São Paulo, SESC,juIho, 1976. Documento 1.

$07 . \quad$ Sugestão de Diretrizes para uma Política Nacional de Lazer, Série Lazer n? 2, São Paulo, SESC, 1980, p. 21 - 99.

08. SALGADO, Marcelo Antonio. Velhice uma Nova Questão Social, Série Terceira Idade, São Paulo, SESC, 1980, p. $21-117$.

09. TEIXEIRA, Gilberto. Perspectivas do Lazer na próxima Década, Cadernos de Lazer n 0 2, São Paulo, Bra siliense, p. $13-21$. 
QUEIROZ, J. B. e Colaboradora - Influência do Lazer Sobre Pessoas da Terceira Idade. Rev. Bras. Enf: RS, 36: 95-106 , 1983.

\section{A NEXO I}

Bauru, 24 de abril de 1982.

O objetivo deste é solicitar de V. Sa. a permissão de u ma visita de nossas ahunas nessa Benemerita Instituição. São ahunas do curso de Graduação em Enfermagem e estão elaborando um trabalho de pesquisa junto às pessoas idosas. A pesquisa estará isenta de identificação.

$\mathrm{Na}$ visita serão obtidas informações, relacionadas a dados gerais da Instituição das pessoas idosas que a freqüenta e posteriormente informações colhidas, com questionário respondido pelos idosos.

Contando com a valiosa colaboração de V. Sa., aproveitamos o ensejo para reiterar nossos protestos de estima e consideração.

Atenciosamente, 
QUEIROZ, J. B. e Colaboradora - Influência do Lazer Sobre Pessoas da Terceira Idade. Rev. Bras. Enf: RS, 36: $95-106,1983$.

\section{A N E XO II \\ QUESTIONÅRIO}

Pretende-se com este questionário avaliar a influência e a importância do lazer na vida cotidiana das pessoas idosas. Para isto queremos que você leia e responda este questionário assinalando com (x) a resposta que julgar a mais correta.

01. Procurou participar de atividades de lazer, por que se sentia sozinho?
( ) sim
( ) não

02. Sempre que tem um tempo livre, procura fazer alguma coisa?
( ) sim
( ) não

03. Sente-se incentivado para procurar o lazer?
( ) sim
( ) não

04. A atividade de lazer que escolhe é realmente do seu agrado?
( ) $\operatorname{sim}$
( ) não

05. Através das atividades de lazer descobriu alguma que lhe dá maior prazer?
( ) $\operatorname{sim}$
( ) não

06. Sente-se feliz desempenhando atividades de lazer?
( ) sim
( ) não

07. A partir do momento que começou a participar de alguma atividade de lazer, sentiu alguma influência importante onde vive?
( ) $\operatorname{sim}$
( ) não

08. Acha importante estas atividades realizadas, junto com pessoas da mesma idade?
( ) $\operatorname{sim}$
( ) não

09. Para você, os jovens aceitam a pessoa idosa?
( ) sim
( ) não

10. Sente que o jovem rejeita o idoso?
( ) sim
( ) não

11. Procura o lazer como um passatempo sem finalidade?
( ) $\operatorname{sim}$
( ) não

12. Procura o lazer como uma fuga da solidão?
( ) sim
( ) não

13. Foi uma pessoa que sentiu-se realizada durante a sua vida no trabalho que fazia?
( ) sim
( ) não

14. Preocupou-se com o lazer também quando era mais novo?

$\begin{array}{ll}\text { ( ) } \operatorname{sim} & \text { ( ) não }\end{array}$

15. Incentivou os companheiros para atividade de lazer também quando era mais novo?
( ) $\operatorname{sim}$
( ) não 